\title{
ANÁLISE COMPARATIVA DA CONCENTRAÇÃO DE DIÓXIDO DE ENXOFRE VIA MODELOS REGULATÓRIOS AERMOD E CALPUFF E MONITORAMENTO PRÓXIMO ÀS FONTES DE EMISSÃO DA BACIA AÉREA III - RMRJ
}

\author{
MAURICIO SOARES DA SILVA ${ }^{1}$, BRUNO D'AIUTO DA CUNHA ${ }^{2}$, LUIZ CLAUDIO GOMES \\ PIMENTEL ${ }^{1,3}$, JESÚS SALVADOR PÉREZ GUERRERO $^{4}$, PEDRO CAFFARO VICENTINI ${ }^{5}$
}

\author{
${ }^{1}$ Universidade Federal do Rio de Janeiro, Instituto Alberto Luiz Coimbra de Pós-Graduação e Pesquisa de Engenharia \\ (UFRJ/COPPE), Programa de Engenharia Mecânica, Rio de Janeiro, RJ, Brasil. \\ ${ }^{2}$ COPPE/UFRJ, Programa de Engenharia Civil, Rio de Janeiro, RJ, Brasil. \\ ${ }^{3}$ UFRJ, Instituto de Geociências (IGEO), Departamento de Meteorologia, Rio de Janeiro, RJ, Brasil. \\ ${ }^{4}$ Comissão Nacional de Energia Nuclear, Coordenação de Rejeitos Radioativos, (CNEN, COREJ/DRS/), Rio \\ de Janeiro, RJ, Brasil. \\ ${ }^{5}$ PETROBRAS, Centro de Pesquisas e Desenvolvimento Leopoldo Américo Miguez de Mello (CENPES), \\ Rio de Janeiro, RJ, Brasil.
}

soares@lamma.ufrj.br,brunodaiuto@lamma.ufrj.br, pimente165@gmail.com,jperez@cnen.gov.br, pcvicentini@ petrobras.com.br

Recebido Maio de 2012 - Aceito Agosto de 2013

\begin{abstract}
RESUMO
A Região Metropolitana do Rio de Janeiro (RMRJ) pode ser caracterizada como uma área afetada por diferentes e complexos mecanismos atuantes na dispersão de poluentes, e que vem sendo submetida a profundas transformações no cenário de emissões atmosféricas. Desta forma uma avaliação das atuais ferramentas indicadas pelos órgãos responsáveis na modelagem regulatória para a obtenção de novos licenciamentos ambientais se torna necessária, principalmente, devido ao atual debate da comunidade científica internacional a respeito do uso destas ferramentas. Nesse contexto, os modelos regulatórios de qualidade do ar AERMOD e CALPUFF tiveram seu desempenho avaliado numa aplicação para a RMRJ em condições de modelagem tipicamente aplicáveis para situações nas proximidades das fontes de emissão. As avaliações estatísticas demonstraram um melhor desempenho do CALPUFF para a Bacia Aérea III desta região, sendo os resultados de suas simulações mais conservadores e com uma tendência para superestimar as concentrações, enquanto os resultados do AERMOD apresentaram a tendência de subestimar as concentrações. Para todos os critérios de avaliação, os resultados do CALPUFF demonstraram ser mais realísticos para a estimativa das concentrações de dióxido de enxofre, quando submetidos às condições locais de dispersão durante o período analisado, indicando ser uma ferramenta adequada para uma melhor gestão da qualidade do ar na Bacia Aérea III da RMRJ. Palavras-chave: Modelagem da qualidade do ar, avaliação de modelos regulatórios, AERMOD, CALPUFF, Bacia Aérea III, Rio de Janeiro, near field.
\end{abstract}

\footnotetext{
ABSTRACT: COMPARATIVE ANALYSIS OF SULFUR DIOXIDE CONCENTRATION BY AERMOD AND CALPUFF REGULATORY MODELS AND MONITORING DATA NEAR THE EMISSION SOURCES AT AIR BASIN III - MRRJ

The Rio de Janeiro Metropolitan Region (RJMR) can be characterized as a region affected by distinct and complex mechanisms concerning atmospheric pollutants dispersion and it has been submitted to great transformations in atmospheric emissions configuration. Therefore an evaluation of the current tools, indicated by the local environment agencies for regulatory modeling to obtain new environmental licenses becomes important mainly due to recently
} 
discussions by the scientific community concerning modeling practices. In the present context, the air quality regulatory models AERMOD and CALPUFF had their performance evaluated using a typical near field modeling configuration applied to the RJMR. The statistical results showed a better performance of the CALPUFF model than the AERMOD model when applied to the Air Basin III. CALPUFF model shows a more conservative simulation of the problem, with higher concentrations values, while the use of AERMOD model resulted in lower concentrations values. For all evaluation criteria CALPUFF demonstrated to be more realistic in the estimation of the sulfur dioxide concentration when submitted to local dispersions conditions at the studied period, suggesting it is adequate to the RJMR Air Basin III air quality management.

Keywords: Near-field, AERMOD, CALPUFF, Air Basin III, Rio de Janeiro, air quality modeling, regulatory models.

\section{INTRODUÇÃO}

O Rio de Janeiro detém um PIB aproximado de U\$125 bilhões, ocupando a segunda posição no ranking nacional (12,6\% do PIB brasileiro), sendo o setor petrolífero o de maior destaque no cenário econômico brasileiro, respondendo por mais de $80 \%$ da produção nacional de petróleo (INEA, 2009). As recentes descobertas de petróleo na camada do pré-sal representam uma real possibilidade do aumento da produção e refino do petróleo em alguns anos, acarretando um incremento na demanda das atividades petroquímicas (MME, 2009) e conduzindo à necessidade do aprofundamento das discussões sobre a viabilidade e necessidade de adequação das ferramentas de gestão da qualidade do ar no Estado. Segundo os critérios estabelecidos pelo Instituto Estadual do Ambiente (INEA), as principais atividades industriais em operação no RJ são consideradas de alto ou médio potencial poluidor, sendo a Região Metropolitana do Rio de Janeiro (RMRJ) e a Região do Médio Paraíba (RMP) consideradas prioritárias com relação a ações de controle da qualidade do ar.

A RMRJ possui uma grande concentração de fontes de emissão de poluentes atmosféricos, apresentando níveis de comprometimento da qualidade do ar em algumas áreas, as quais requerem um sistema de monitoramento mais abrangente (INEA, 2009). A RMRJ apresenta a segunda maior concentração de veículos e indústrias do Brasil com uma grande densidade de emissões de poluentes. De acordo com o inventário da região reportado pela antiga FEEMA, as fontes móveis representam de uma forma geral $77 \%$ do total das emissões de poluentes, enquanto as fontes estacionárias contribuem com cerca de $23 \%$ (FEEMA, 2004). Esse quadro se inverte quando considera-se o poluente dióxido de enxofre $\left(\mathrm{SO}_{2}\right)$, sendo $88 \%$ das emissões provenientes das fontes fixas e apenas $12 \%$ são oriundas de fontes veiculares (FEEMA, 2004). Entre as fontes estacionárias, a indústria petroquímica possui uma maior contribuição nas emissões de poluentes na RMRJ com $51 \%$ de $\mathrm{SO}_{2}, 38 \%$ de
$\mathrm{NO}_{\mathrm{x}}$ e $90 \%$ de Compostos Orgânicos Voláteis (COV). A RMRJ é influenciada diretamente por fenômenos de circulação locais e sinóticos que afetam a configuração do regime de vento na região, dada sua topografia complexa, a presença de corpos d'água e a ocupação irregular do solo, fornecendo condições não-homogêneas para a dispersão atmosférica de poluentes. Na região há ocorrência de fenômenos de diferentes escalas espaciais e temporais, como a atuação do Anticiclone Subtropical do Atlântico Sul (ASAS), ocorrência de Sistemas de Baixa Pressão como as Frentes Frias, Zona de Convergência do Atlântico Sul (ZCAS), atividades convectivas, sistema de brisas marítima/terrestre e de vale/montanha. No período de maio a setembro, devido à atuação dos sistemas de alta pressão que dominam a região, ocorrem com frequência situações de estagnação atmosférica e elevados índices de poluição. Além desses fatores, ainda deve ser considerado que a região está sujeita às características do clima tropical, com intensa radiação solar e temperaturas elevadas, favorecendo os processos fotoquímicos e outras reações na atmosfera, contribuindo para a geração de poluentes secundários como os oxidantes fotoquímicos e aerossóis. Considerando a influência topográfica e meteorológica da RMRJ, o INEA dividiu a região em quatro sub-regiões como estratégia de planejamento e gestão ambiental. Essas áreas, delimitadas pela topografia e os espaços aéreos na horizontal e na vertical, constituem uma Bacia Aérea, conforme apresentado na Figura 1.

Segundo o INEA (2009) a Bacia Aérea III se destaca das demais sub-regiões por abrigar as fontes fixas que mais contribuem para a emissão de poluentes na RMRJ (Tabela 1) e as principais concentrações de fontes móveis da região. Nessa subregião são registradas as maiores ocorrências de concentração de poluentes com rotineira violação do padrão primário da qualidade do ar referente aos poluentes ozônio $\left(\mathrm{O}_{3}\right)$ e partículas inaláveis $\left(\mathrm{PM}_{10}\right)$, se mostrando importante a aplicação adequada de ferramentas de gestão da qualidade do ar. O cenário exposto, considerando os níveis de degradação da qualidade do ar na 


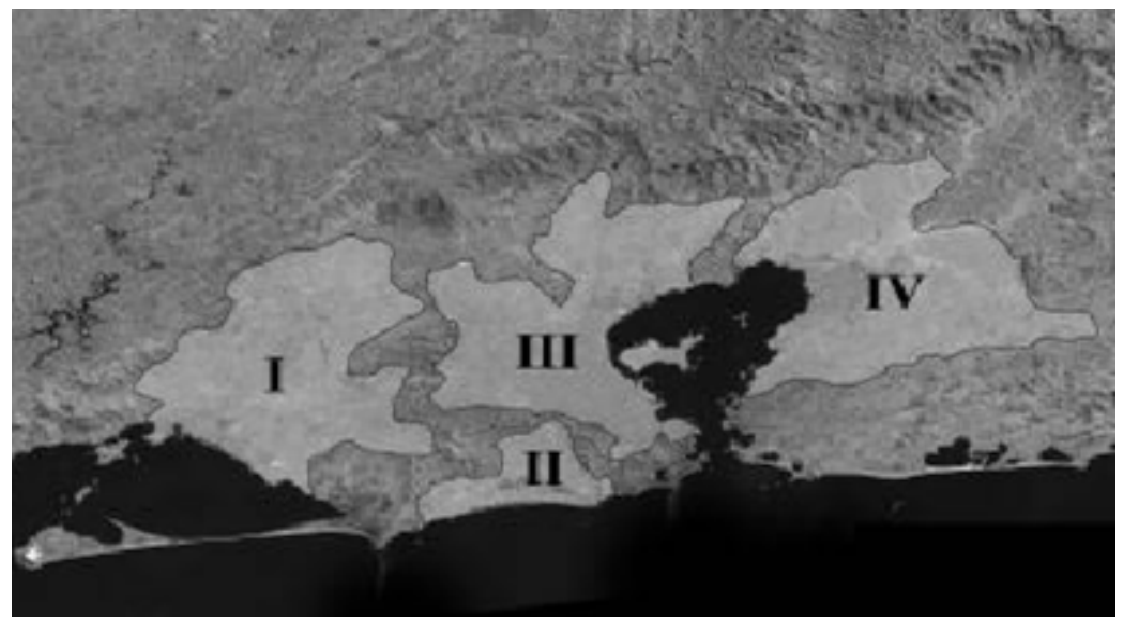

Figura 1 - Delimitação das Bacias Aéreas da RJMR. Fonte: INEA, 2009.

Bacia Aérea III e a importância socioeconômica e cultural da sub-região, sendo a principal área onde estarão concentrados nos próximos anos os maiores eventos esportivos do mundo, como a Copa do Mundo de 2014 e as Olimpíadas de 2016, evidencia a urgência em se consolidar ações de controle ambiental, incluindo a avaliação e adequação dos modelos de qualidade do ar para uso nessa sub-região.

Durante as décadas de 80 e 90, a agência ambiental americana, denominada United States Environmental Protection Agency (USEPA), promoveu diversos estudos em conjunto com a comunidade científica, com o objetivo de avaliar e comparar o desempenho dos diversos modelos de qualidade do ar, para desse modo subsidiar a recomendação destes para uso regulatório. Nesses estudos foram considerados modelos com concepção gaussiana e lagrangeana, e na abordagem incluía a avaliação das limitações e potencialidades dos modelos, focando suas aplicações específicas para uso regulatório (USEPA, 2003; Venkatram et al., 2004; Sidle et al., 2004; Balanescu et al., 2004; Perry et al., 2005; Elbir, 2003; YAU et al., 2004;
Moraes, 2004; Oshan et al., 2006 e Velloso, 2007). Os estudos apontaram para a necessidade da continuidade da avaliação para outras áreas urbanas do mundo, indicando que as análises não destacaram um consenso sobre o desempenho dos modelos.

Em 2005 a USEPA publicou no seu código de leis administrativas federais uma nova recomendação para aplicações regulatórias com modelos de qualidade do ar (USEPA, 2005), com a finalidade de garantir a consistência das análises de qualidade do ar, recomendando modelos específicos em consonância com cada situação de dispersão atmosférica. No documento, o modelo American Meteorological Society/ Environmental Protection Agency Regulatory Model (AERMOD) (USEPA, 2004) foi recomendado, em substituição ao modelo Industrial Source Complex (ISC, USEPA, 1995), para uso em aplicações regulatórias em situações onde a análise da dispersão de poluentes está concentrada nas proximidades das fontes de emissão. Esse cenário é denominado em inglês como situação near field, onde os receptores estão localizados em um raio de até $50 \mathrm{~km}$ das fontes de emissão. O modelo

Tabela 1 - Taxa de Emissão por Bacia Aérea (x1000 ton/ano).

\begin{tabular}{l|c|c|c|c|c}
\hline \multicolumn{1}{c|}{$\begin{array}{c}\text { Taxa de Emissão } \\
\text { (ton/ano)*1000 }\end{array}$} & $\mathbf{S O}_{\mathbf{2}}$ & $\mathbf{N O}_{\mathbf{x}}$ & $\mathbf{C O}$ & $\mathbf{H C}$ & $\mathbf{P M}_{\mathbf{1 0}}$ \\
\cline { 2 - 6 } Total Geral & 55.76 & 30.27 & 6.38 & 25.85 & 10.58 \\
\hline Bacia Aérea I & 21.48 & 14.55 & 0.92 & 0.31 & 5.90 \\
\hline Bacia Aérea II & 0.01 & 0.14 & 0.13 & 0.74 & 0.36 \\
\hline Bacia Aérea III & 29.41 & 13.30 & 2.80 & 24.44 & 2.50 \\
\hline Bacia Aérea IV & 3.80 & 1.28 & 2.36 & 0.13 & 1.39 \\
\hline
\end{tabular}

Fonte: INEA (2009). 
California Puff Model (CALPUFF, SCIRE, 2000b) foi recomendado para estudos onde os receptores se encontravam a distâncias superiores a $50 \mathrm{~km}$ das fontes, ou ainda, como um modelo auxiliar para distâncias inferiores a $50 \mathrm{~km}$, onde o transporte de poluentes ocorre sob a atuação de circulação complexa, induzida pela heterogeneidade do terreno e caracterizada pela variabilidade espacial do regime de vento.

Esta opção de uso do CALPUFF como modelo alternativo em aplicações near field é sujeita a aprovação das autoridades legais caso a caso, quando se determina que o AERMOD não é apropriado ou menos apropriado que o CALPUFF. O modelo alternativo pode ser aplicado desde que alguns critérios sejam apresentados como: o modelo tenha sido avaliado cientificamente de forma criteriosa; seja demonstrado que o modelo possa ser aplicado ao problema de forma teórica; as bases de dados necessárias para realizar avaliação são disponíveis e adequadas; apropriadas avaliações de desempenho do modelo demonstram que este não está inclinado a subestimativas; e que um protocolo de métodos e procedimentos a serem seguidos tenha sido estabelecido. Deve-se destacar, que recentes estudos realizados pela comunidade científica tem iniciado uma discussão sobre uma nova proposta de modelagem da qualidade do ar para aplicações regulatórias. Nessas avaliações, propõe-se o uso do CALPUFF em substituição ao modelo regulatório AERMOD, mesmo para cenários de avaliação da dispersão de poluentes nas proximidades das fontes de emissão (USEPA, 2008; Donaldson et. al., 2008 e Pimentel et al., 2010). No recente estudo proposto por Brode (2012), destaca-se que para situações near field, a utilização do modelo CALPUFF ainda não se encontra bem documentada, embora o tema venha sendo debatido pelas autoridades responsáveis. Apesar de Brode (2012) destacar que em sua avaliação o CALPUFF apresentou melhor desempenho que o AERMOD, o autor indica que os resultados não demonstraram claramente a maior habilidade do modelo lagrangeano, evidenciando a necessidade de avaliação para cada situação específica. Apesar da grande quantidade de modelos que têm sido disponibilizados mundialmente nos últimos anos, capazes de estimar a concentração de poluentes para uma variada gama de situações, no Brasil ainda não foi definido um padrão criterioso de avaliação do desempenho e aplicabilidade desses modelos. Segundo Moreira e Tirabassi (2004), a utilização dos modelos de dispersão de poluentes atmosféricos não pode prescindir de um estudo sobre a sua representação dos fenômenos que ocorrem na região do estudo. Os autores ainda destacam que modelos adequados para as regiões dos EUA podem não apresentar o mesmo desempenho quando aplicados para situações específicas no Brasil. Nota-se com base nos diversos estudos realizados no mundo e na carência de estudo para o Brasil, que para melhor compreender os efeitos dessas emissões de poluentes atmosféricos sobre a qualidade ambiental da região, se faz necessário a avaliação das ferramentas regularmente utilizadas pelos órgãos ambientais brasileiros.

O principal objetivo deste estudo é avaliar comparativamente o desempenho dos modelos regulatórios AERMOD e CALPUFF para aplicação nas proximidades das principais fontes de emissão de dióxido de enxofre instaladas na Bacia Aérea III da Região Metropolitana do Rio de Janeiro.

\section{MATERIAIS E MÉTODOS}

\subsection{Período do Estudo}

O período selecionado para as simulações com os modelos de qualidade do ar foi escolhido principalmente para atender a disponibilidade de dados do inventário de emissão de poluentes, informações sobre o monitoramento meteorológico e da qualidade do ar. A análise se concentrou no período de inverno onde normalmente são detectados os maiores níveis de concentração de poluentes e foi desenvolvida considerando o período de primeiro de Julho a vinte e nove de Setembro de 2008, perfazendo aproximadamente três meses de simulações para a avaliação do modelo. O foco principal do estudo está associado à avaliação comparativa do desempenho entre os modelos AERMOD e CALPUFF, e não no uso regulatório desses modelos para a avaliação de violação dos padrões de qualidade do ar na RMRJ. Dessa forma, apesar de considerar importante a análise com série de dados para períodos mais longos, a ausência dessas informações para a RMRJ não inviabiliza o estudo. Deve-se destacar que diversos estudos, disponibilizados na literatura científica, subsidiaram a obtenção de evidências sobre o desempenho comparativo entre modelos de qualidade do ar a partir de informações de séries temporais de concentração de poluentes para períodos inferiores a um ano (Venkatram et al., 2004; Yau et al., 2004; Perry et al., 2005; Vicentini, 2011; USEPA, 2012; Seangkiatiyuth et al., 2011).

\subsection{Inventário das Emissões Fixas e Veiculares}

O inventário de fontes emissoras é uma informação determinante para o sucesso da modelagem da qualidade do ar, estando diretamente relacionado à representatividade dos resultados da concentração atmosférica simulada. Em diversos estudos de modelagem da qualidade do ar, a má representação é em boa parte atribuída à baixa qualidade e falta de atualização dos inventários de emissões (Vicentini, 2011). No presente estudo foi utilizado o inventário de emissões de fontes fixas (industriais) e móveis (veiculares) proposto por Vicentini (2011) para a RMRJ. Neste inventário foram consideradas as principais atividades poluidoras de origem fixa e móvel registradas no ano de 2007, referente a região de estudo. As fontes caracterizadas 


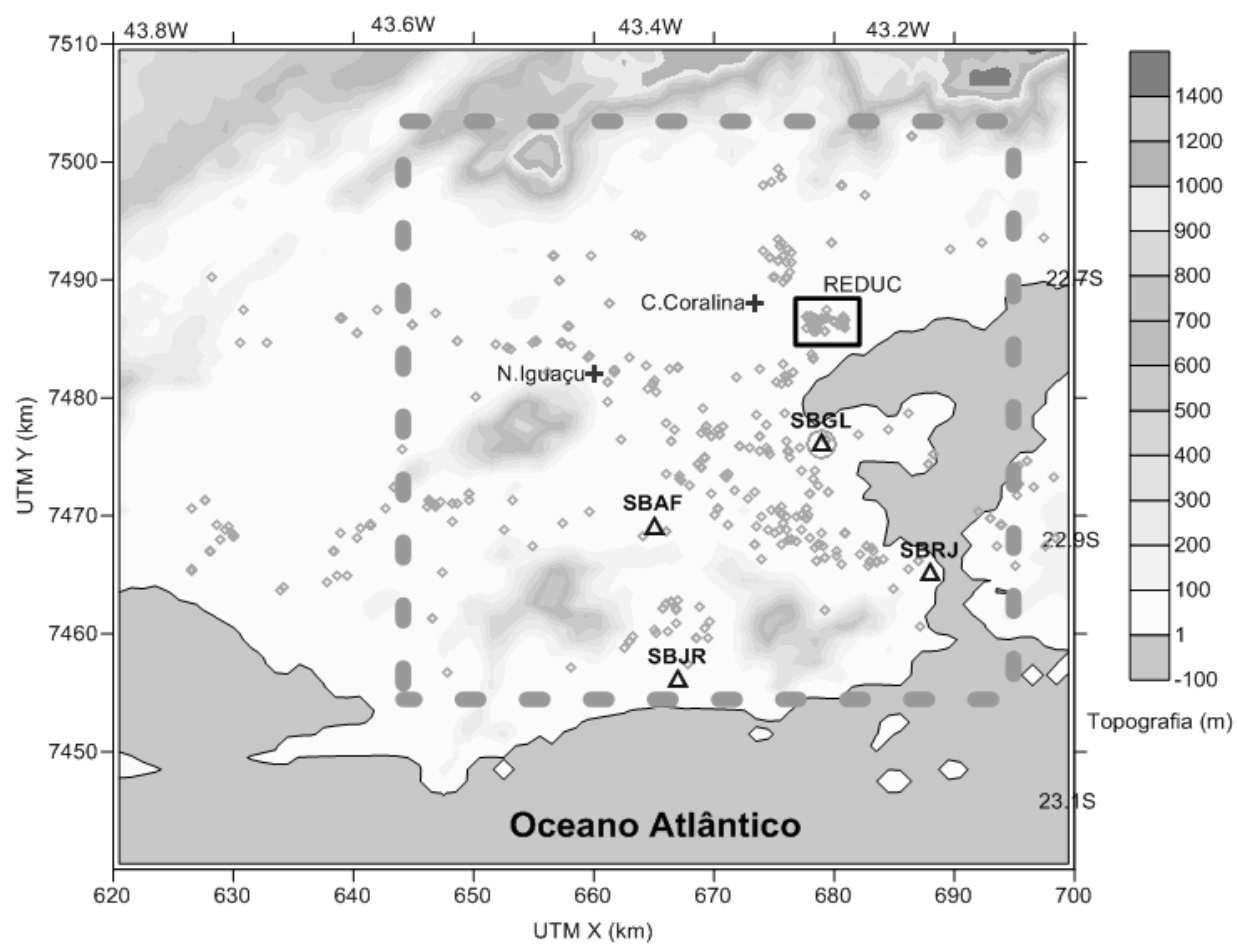

Figura 2 - As cruzes representam as estações de monitoramento de qualidade do ar de Nova Iguaçu e Cora Coralina, o retângulo em preto a REDUC e os triângulos e círculos representam as estações meteorológicas de superfície e altitude respectivamente utilizadas no estudo. Os losangos representam as fontes fixas utilizadas no estudo. O domínio modelado é delimitado pela linha tracejada.

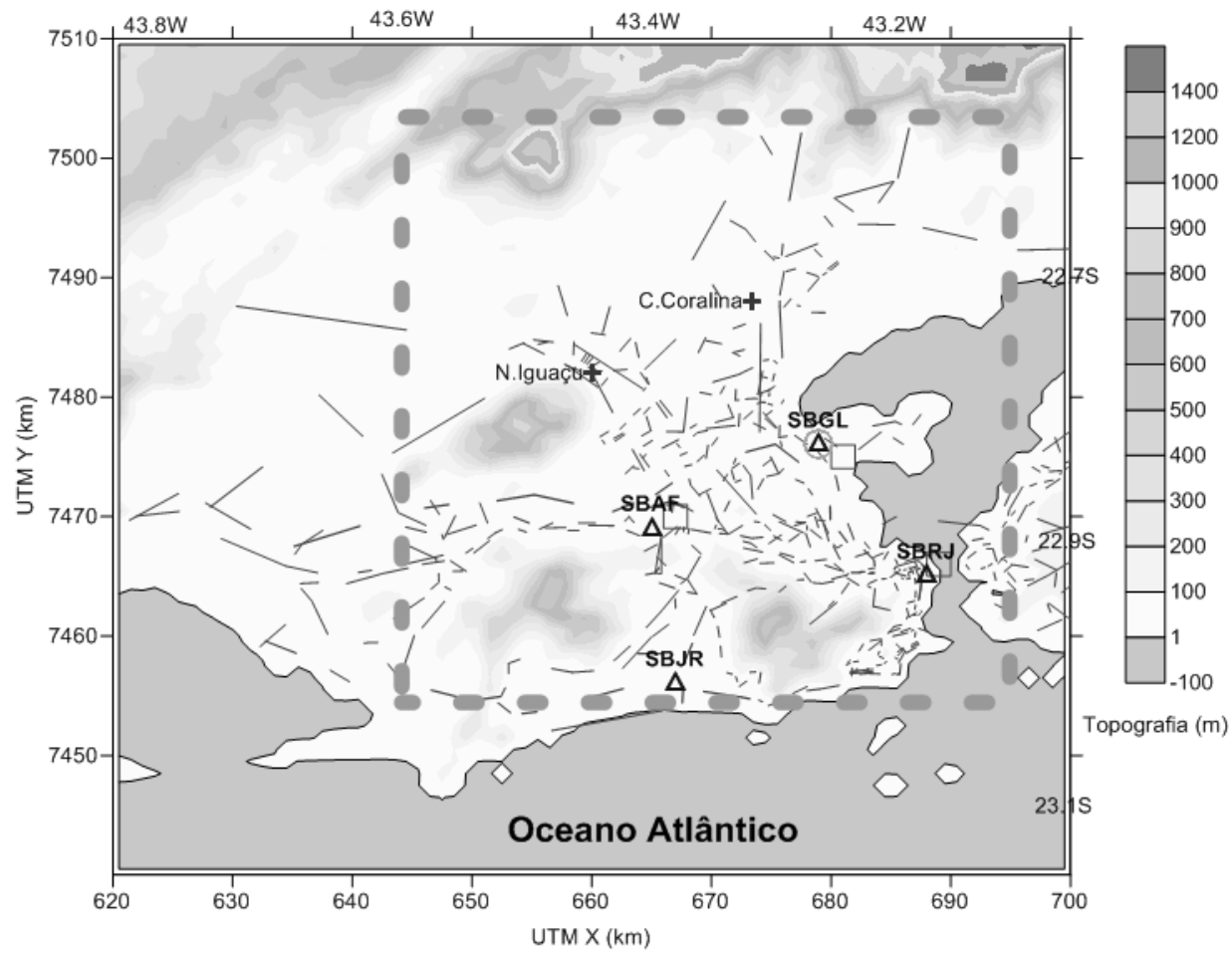

Figura 3 - As cruzes representam as estações de monitoramento de qualidade do ar de Nova Iguaçu e Cora Coralina, os triângulos e círculos representam as estações meteorológicas de superfície e altitude respectivamente utilizadas no estudo. Os segmentos de reta representam as fontes móveis utilizadas no estudo. O domínio modelado é delimitado pela linha tracejada. 
como fontes fixas (indústrias) foram configuradas nos modelos como fontes pontuais (Figura 2), enquanto que as caracterizadas como fontes móveis (veiculares) foram configuradas como fontes área (Figura 3).

O poluente dióxido de enxofre $\left(\mathrm{SO}_{2}\right)$ foi escolhido para o estudo devido a sua emissão ser preponderantemente oriunda de fontes fixas na área de estudo, conforme citado anteriormente as emissões de $\mathrm{SO}_{2}$ oriundas de fontes fixas correspondem a aproximadamente $88 \%$ do total das emissões de $\mathrm{SO}_{2}$, o que confere uma maior confiabilidade nos dados de inventário de emissão. Deve-se ressaltar que apesar dos avanços na estimativa dos inventários de emissão provenientes de fontes móveis (Vicentini et al., 2011), devido a vasta gama de parâmetros necessários para a sua estimativa, ainda ocorre um razoável grau de incerteza na determinação desse parâmetro. Assim, a escolha do poluente $\mathrm{SO}_{2}$ para o estudo busca reduzir as incertezas nos resultados das simulações decorrentes dos possíveis erros associados às incertezas das fontes de emissão inventariadas. Deve-se destacar que a escolha de poluentes como monóxido de carbono e óxidos de nitrogênio, que reconhecidamente apresentam significativas emissões veiculares (Vicentini et al., 2011), comprometeriam a comparação dos resultados simulados com os dados do monitoramento da concentração desses poluentes. Além disso, o AERMOD e CALPUFF são considerados modelos regulatórios para fontes industriais e apesar de serem sistematicamente utilizados para a assimilação de dados de emissão de fontes móveis, como proposto no estudo, a confiabilidade dos resultados é melhor assegurada para estudos onde prioritariamente as emissões atmosféricas estão associadas as fontes fixas.

\subsection{Descrição e Configuração dos Modelos de Qualidade do Ar}

O AERMOD é um modelo Gaussiano de última geração que fornece resultados de concentração proveniente da dispersão de poluentes atmosféricos (USEPA, 2004). O modelo utiliza um processador de dados meteorológicos de superfície e ar superior, denominado Aermod Meteorological Preprocessor (AERMET), para estimativa de parâmetros da Camada Limite Atmosférica (CLA), tais como: velocidade de fricção, comprimento de Monin-Obukhov, escala de velocidade convectiva, escala de temperatura, altura de mistura convectiva, altura de mistura mecânica e fluxo de calor na superfície. Na modelagem pode-se inserir o efeito do transporte de poluentes sobre terrenos complexos a partir da assimilação e tratamento de dados de modelo de elevação digital do terreno (DEM), com auxílio do pré-processador Aermod Terrain Preprocessor (AERMAP).

O sistema de modelagem CALPUFF é composto por três módulos: o modelo meteorológico diagnóstico CALMET, o modelo de dispersão de poluentes atmosféricos CALPUFF e um módulo de pós-processamento denominado CALPOST (Scire et al., 2000a e 2000b). O CALMET possibilita gerar campos tridimensionais de vento e de temperatura e os mesmos parâmetros micrometeorológicos da CLA estimados pelo AERMET. Os dados de entrada do módulo CALMET são as variáveis meteorológicas de superfície e de ar superior, obtidos a partir do monitoramento e/ou com auxílio de resultados de modelos prognósticos e de informações do terreno. O módulo de dispersão de poluentes do CALPUFF é baseado na descrição Lagrangeana de puff Gaussiano transiente, cuja principal característica é simular os efeitos de variação das condições meteorológicas sobre o transporte de poluentes, além de modelar situações de calmaria. O CALPOST processa os dados dos arquivos de saída do CALPUFF, organizando e produzindo um resumo dos resultados das simulações.

O domínio definido para modelagem em ambos os modelos foi de 50 x $50 \mathrm{~km}$ (Figura 2 e 3), dimensões estas definidas com o intuito de satisfazer a condição near field. $\mathrm{O}$ domínio abrange a Bacia Aérea III, considerada pelo INEA a área mais saturada pela presença de poluentes (FEEMA, 2004). A escolha da resolução do espaçamento de grade na simulação com o CALPUFF foi baseada no estudo realizado por Soares (2010), no qual o autor obteve os melhores resultados usando um espaçamento de $500 \mathrm{~m}$ entre os pontos de grade. Ainda segundo o autor, apesar da discrepância entre a resolução do arquivo de uso e ocupação do solo $(1000 \mathrm{~m})$ e da resolução utilizada no modelo $(500 \mathrm{~m})$, os resultados considerando essa resolução foram melhores quando comparados com os resultados do modelo, considerando uma resolução de $1000 \mathrm{~m}$. Na modelagem com o AERMOD foi utilizada a mesma resolução de grade do CALPUFF, mesmo não se esperando alterações relevantes devido ao efeito de diferentes resoluções, visto que o modelo não permite a representação de variações espaciais devido ao regime de vento e categoria de uso do solo. No entanto, essa configuração facilita a comparação dos resultados em um mesmo ponto de grade do domínio da simulação. Na Tabela 2 estão apresentadas as principais configurações dos modelos.

Seguindo os propósitos regulatórios, os processos de remoção úmida e seca, transformações químicas, e efeitos de construções próximas das fontes emissoras (Building Downwash) não foram considerados nas simulações. As parametrizações baseadas na teoria da similaridade foram selecionadas para a estimativa dos coeficientes de dispersão usados nos modelos.

\subsection{Dados Meteorológicos de Superfície e Altitude}

Informações meteorológicas observadas em superfície e ar superior relativas ao período de estudo foram inseridas 
(a)

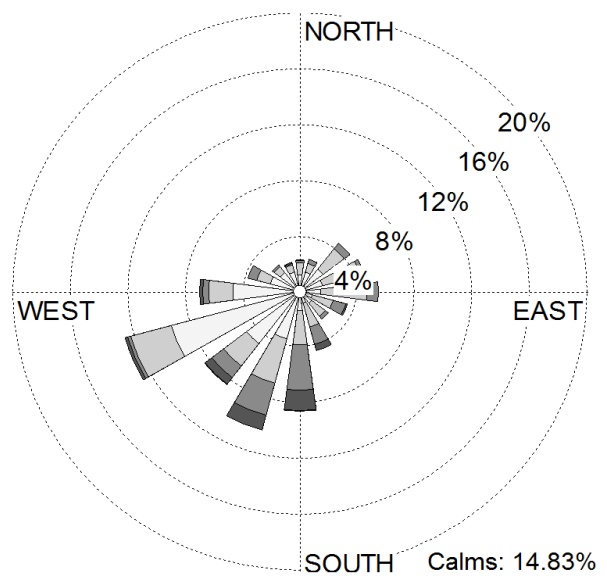

(b)

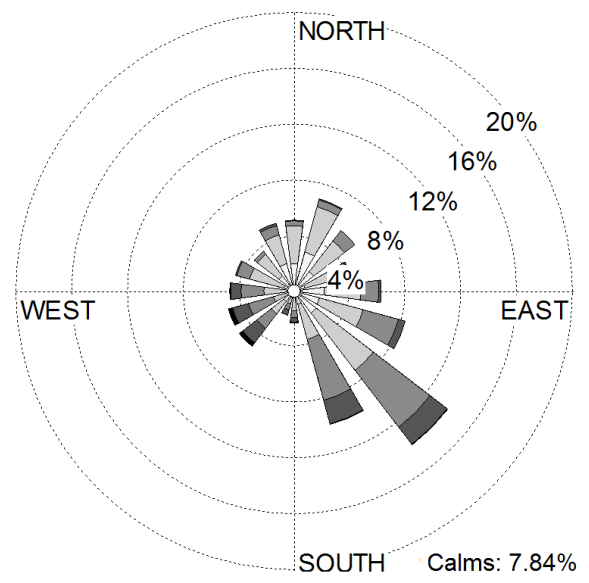

(c)

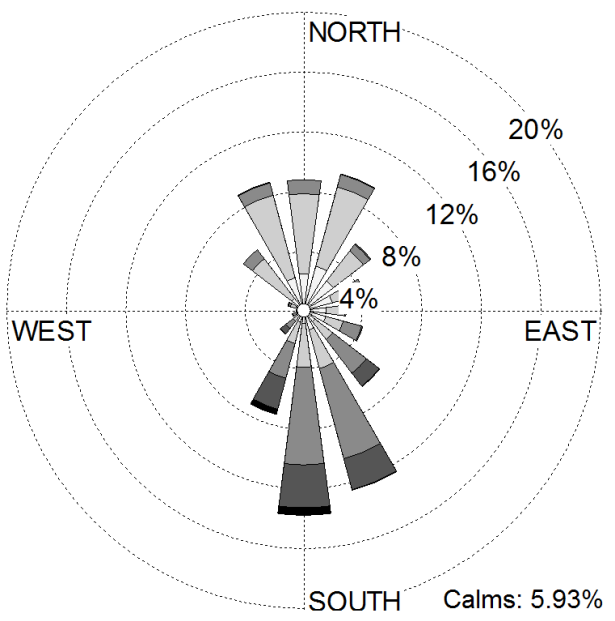

(d)

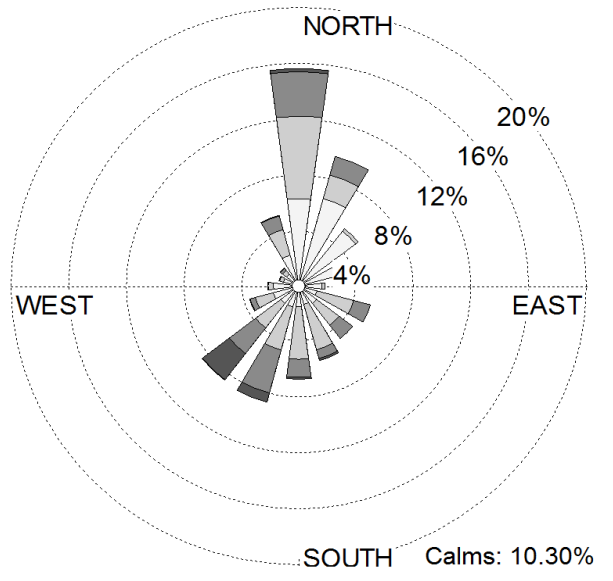

Vel. Vento $(\mathrm{m} / \mathrm{s})$

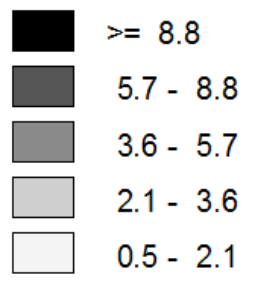

Figura 4 - Rosas dos ventos das estações: SBAF (a), SBGL (b), SBRJ (c) e SBJR (d). 
Tabela 2 - Principais configurações dos modelos AERMOD e CALPUFF.

\begin{tabular}{l|c|c|}
\hline \multicolumn{1}{|c|}{ Parâmetros } & AERMOD & CALPUFF \\
\hline Estações de superfície & SBGL & SBGL, SBAF, SBJR, SBRJ \\
\hline Estações de altitude & SBGL & SBGL \\
\hline Remoção Úmida & não & não \\
\hline Remoção Seca & não & não \\
\hline Transformações Químicas & não & não \\
\hline Building Downwash & não & não \\
\hline Resolução do arquivo digital do terreno & $90 \mathrm{~m}$ & $90 \mathrm{~m}$ \\
\hline Resolução do uso e ocupação do solo & - & $1000 \mathrm{~m}$ \\
\hline Resolução de grade & $500 \mathrm{~m}$ & $500 \mathrm{~m}$ \\
\hline Domínio & $50 \times 50 \mathrm{~km}$ & $50 \times 50 \mathrm{~km}$ \\
\hline Níveis Verticais & - & 12 \\
\hline
\end{tabular}

nos modelos, sendo que devido à diferença entre a concepção física dos modelos, o AERMOD utilizou dados de superfície referente ao código METAR proveniente de apenas um local de monitoramento, localizado no Aeroporto Internacional Antônio Carlos Jobim (SBGL). No CALPUFF foram utilizados dados de superfície do código METAR provenientes de 4 estações meteorológicas: Aeroporto Antônio Carlos Jobim (SBGL), Campo dos Afonsos (SBAF), Aeroporto de Jacarepaguá (SBJR) e Aeroporto Santos Dumont (SBRJ). O dado meteorológico de altitude utilizado nos modelos foi obtido do sítio http:// weather.uwyo.edu/upperair/sounding.html referente à estação de monitoramento instalada no Aeroporto Internacional Antônio Carlos Jobim (SBGL), via radiossondagem da atmosfera.

\subsection{Base de dados topográficos e de uso do solo}

Em ambos os modelos foram utilizados dados topográficos com resolução de $90 \mathrm{~m}$, obtidos do modelo digital de elevação SRTM (Shuttle Radar Topography Mission) oriundos da base de dados CGIAR-CSI (Consortium for Spatial Information - Consultative Group for International Agriculture Research). Informações de uso e ocupação do solo com resolução aproximada de $1000 \mathrm{~m}$ foram extraídas da fonte GLCC (Global Land Cover Characterization) e inseridas no modelo CALPUFF. Devido às limitações do modelo AERMOD na representação de diferenciados tipos de uso e ocupação do solo, foram considerados os seguintes valores de características da superfície para toda a área modelada: 0,16 para albedo, 1,00 m para rugosidade e 2,00 para Razão de Bowen.

\subsection{Avaliação dos Resultados e Localização dos Receptores}

A avaliação dos resultados obtidos com o AERMOD e CALPUFF foi realizada a partir da comparação com os dados observados nas estações de monitoramento da qualidade do ar do INEA, localizadas nos municípios de Nova Iguaçu e Duque de Caxias denominadas no presente trabalho como Nova Iguaçu e Cora Coralina, esta última pertencente a rede da Refinaria de Duque de Caxias - REDUC (Figura 2). Quanto a disposição espacial entre as estações, destaca-se que a estação de monitoramento de Nova Iguaçu está localizada a uma distância de $20 \mathrm{~km}$ das maiores fontes de emissões industriais da região e apresenta dados horários com 42 dias de medições no período selecionado. A estação de Cora Coralina está localizada a aproximadamente $5 \mathrm{~km}$ dessas fontes e apresentou 84 dias de medições horárias. A grande diferença do espaço amostral entre os dados monitorados nas duas estações se deve a problemas técnicos que ocorreram na estação de Nova Iguaçu. Os índices estatísticos propostos por Hanna (1988), que estão apresentados na Tabela 3, foram utilizados para a avaliação estatística em conjunto com as figuras de dispersão. 
Tabela 3 - Índices estatísticos.

\begin{tabular}{l|l|c}
\hline \multicolumn{1}{c|}{ Índice } & \multicolumn{1}{c|}{ Sigla } & Definição \\
\hline Coeficiente de Correlação & COR & $\frac{\overline{\left(C_{O}-\overline{C_{O}}\right)\left(C_{P}-\overline{C_{P}}\right)}}{\sigma_{O} \sigma_{P}}$ \\
\hline Desvio Fracional Padrão & DFP & $\frac{2\left(\sigma_{P}-\sigma_{O}\right)}{\sigma_{P}+\sigma_{O}}$ \\
\hline Desvio Fracional & DF & $2\left(\frac{\bar{C}_{O}}{\overline{C_{O}}+\overline{C_{P}}}\right)$ \\
\hline Fator de 2 & FA2 & $0.5 \leq \frac{C_{O}}{C_{P}} \leq 2$ \\
\hline Erro Médio Quadrático Normalizado & EMQN & $\frac{\left(C_{P}-C_{O}\right)^{2}}{C_{O} C_{P}}$ \\
\hline
\end{tabular}

(O) observado, (P) predito.

\section{RESULTADOS E DISCUSSÃO}

\subsection{Análise Meteorológica}

Segundo registros do Centro de Previsão de Tempo e Estudos Climáticos - CPTEC ocorreu a atuação de aproximadamente nove sistemas transientes de escala sinótica no RJ durante o período do estudo, proporcionando desde quedas de temperatura a chuvas fortes com rajadas de vento. Em julho constatou-se dois sistemas, sendo uma frente fria que atingiu a parte litorânea da região Sudeste por volta dos dias 24 e 25 , e um cavado em níveis médios e altos no dia 4. No dia 10 de agosto ocorreu a atuação de um sistema de baixa pressão associado a um cavado em níveis médios e altos da atmosfera ocasionando ventos fortes e precipitação intensa. No dia 23 de agosto o ramo frio de um ciclone extratropical atingiu a região ocasionando modificações no tempo, enquanto no dia 30 uma frente fria ocasionou chuva intensa na região. O mês de setembro apresentou que uma distribuição mais regular dos 4 sistemas que nele ocorreram, sendo o primeiro ocorrido no dia 8 , com a passagem de um sistema frontal gerando modificações na atmosfera, ocasionando a precipitação de granizo no dia seguinte à sua passagem. Nos dias 15 e 21 houve a passagem de sistemas frontais clássicos, e no dia 26 ocorreu a atuação de um cavado baroclínico. A análise da Figura 4 indica que em todo o período do estudo não ocorreram valores acentuados de precipitação acumulada diária. Os meses de julho e agosto apresentaram regime similar de precipitação com registro de chuvas isoladas com baixa intensidade. Em setembro, o regime de chuva apresentou um padrão ligeiramente diferente, com quatro períodos regularmente alternados de dias sem precipitação e com precipitação de baixa intensidade.

As rosas de vento obtidas a partir do tratamento dos dados de vento monitorado nas estações de superfície instaladas nos aeroportos são apresentadas na Figura 5. Pode-se notar que para SBAF, que se encontra a aproximadamente $21 \mathrm{~km}$ de distância das principais fontes de emissão, ocorre predomínio das direções Sul e Sudoeste, com velocidade média do vento de $2 \mathrm{~m} / \mathrm{s}$ e percentual de calmaria de $14,83 \%$, como destacado na Figura 5a. De acordo com Pimentel (2014), o posicionamento da estação SBAF, entre os Maciços de Gericinó, Pedra Branca e da Tijuca, confere a esta localidade um padrão de estagnação dos ventos. No SBGL, que se encontra afastado aproximadamente $10 \mathrm{~km}$ das principais fontes de emissão industrial, o padrão de Sudeste é mais evidente, com velocidade media do vento de 2,87 $\mathrm{m} / \mathrm{s}$, sugerindo uma circulação de brisa orientada pela Baía de Guanabara, sendo a ocorrência de calmaria no período avaliado em apenas 7,84\% (Figura 5b). Este padrão de circulação é possivelmente o mais importante na simulação da dispersão de poluentes nesta região, devido a sua maior proximidade das principais fontes de $\mathrm{SO}_{2}$, em comparação às demais estações meteorológicas, sendo responsável pelo transporte advectivo nas proximidades das fontes de emissão. A $24 \mathrm{~km}$ de distância das principais fontes de emissão, encontra-se a estação SBRJ que apresenta um percentual de calmaria de 5,93\%, com um regime de vento nas direções Norte e Sul e velocidade média de 2,98 $\mathrm{m} / \mathrm{s}$ (Figura $5 \mathrm{c}$ ). Este regime de vento encontrado em SBRJ indica uma circulação de brisa marítima/terrestre devido a sua proximidade do Oceano Atlântico, apresentando a maior intensidade do vento com relação aos demais aeroportos. $\mathrm{Na}$ estação SBJR a velocidade média do vento foi de $2,08 \mathrm{~m} / \mathrm{s}$ 


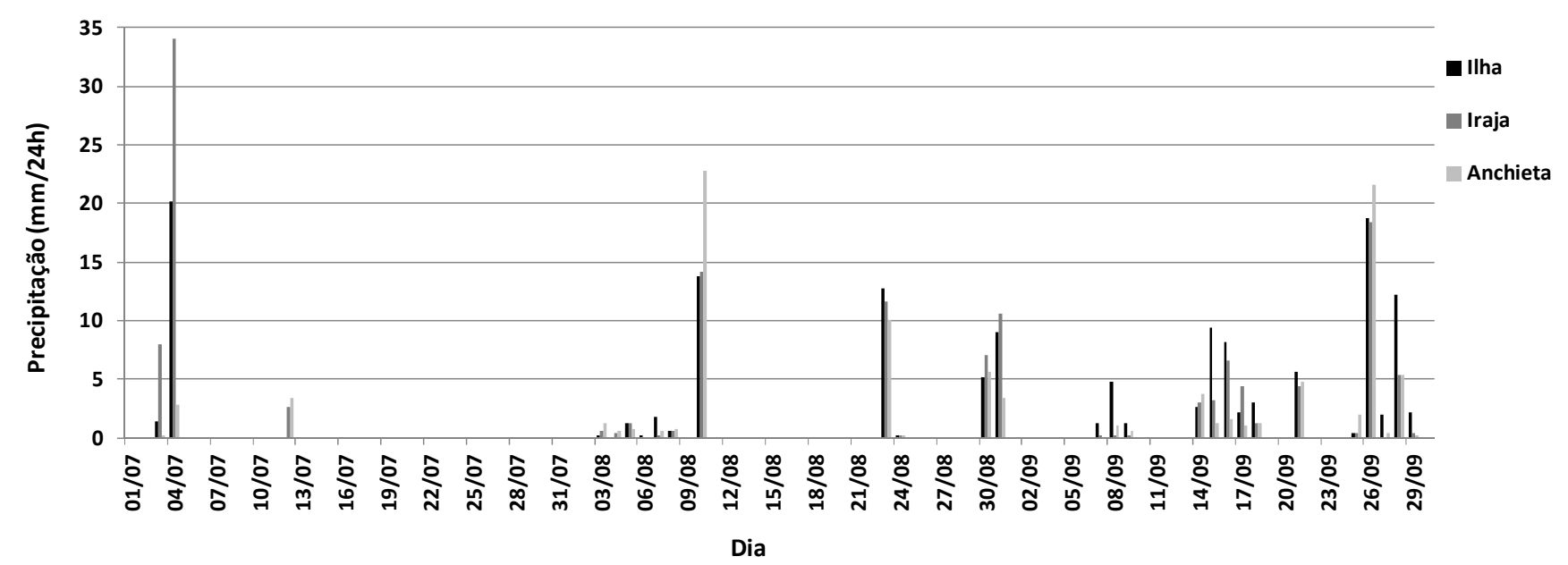

Figura 5 - Precipitação acumulada (mm/24h) registrados nas estações pluviométricas localizadas na Bacia Área III. Fonte: Sistema Alerta Rio.

com registro de frequência de calmaria de 10,30\% (Figura 5d), distando esta estação de $32 \mathrm{~km}$ das principais fontes emissoras. Apesar dos registros de velocidade média do vento indicarem valores similares entre as diferentes estações observacionais, a análise da direção do vento apresenta significativa variabilidade espacial na região do estudo.

\subsection{Análises gráficas das concentrações}

Segundo alguns autores (Venkatram e Wyngaard, 1988; Hanna e Chang, 1993; Zannetti, 1990) a comparação entre resultados simulados de concentração e dados de monitoramento, simultaneamente avaliados em um mesmo tempo e local, não devem ser consideradas rigorosamente como uma análise de desempenho de modelos, principalmente para aqueles com concepção permanente de modelagem, como o AERMOD. Para fins regulatórios uma modelagem satisfatória da qualidade do ar deve apresentar estimativas confiáveis dos picos de concentração, independentemente da acurácia em relação ao local e período da ocorrência (USEPA, 2003). Deve-se destacar que modelos concebidos a partir de uma formulação transiente, em que o cenário de concentração pretérito impacta diretamente na estimativa da concentração futura, podem representar mais realisticamente os locais e períodos de ocorrência desses máximos. O modelo Lagrangeano CALPUFF está inserido nessa classe de modelos.

Na Figura 6 é apresentada a avaliação temporal das concentrações observadas em Nova Iguaçu e Cora Coralina, evidenciando que os padrões nestas estações de monitoramento apresentam uma razoável correlação entre si em termos de variação temporal. Pela análise da Figura 6 nota-se que as concentrações observadas em Cora Coralina apresentaram maiores valores em relação a Nova Iguaçu, este fato pode ser explicado pela menor distância de Cora Coralina das principais fontes de emissão, além dos ventos de Sudoeste observados em SBAF (estação mais próxima de Nova Iguaçu) que dificulta a chegada de poluentes provenientes das principais fontes emissoras de $\mathrm{SO}_{2}$.

$\mathrm{Na}$ análise da Figura 7 verifica-se que para a estação de monitoramento de Nova Iguaçu os resultados dos modelos representaram a variabilidade temporal dos dados medidos, no entanto, deve-se destacar que o AERMOD apresenta sistematicamente os menores valores, com uma clara tendência a subestimava dos dados medidos. Os resultados do CALPUFF indicam alternância dos níveis de concentração com relação aos dados monitorados, em alguns períodos ocorre uma superestimativa desses valores e em outros períodos nota-se uma tendência para subestimar os dados monitorados, principalmente para os picos de concentração ocorridos entre os dias $19 / 08$ a $22 / 08\left(17,8 \mu \mathrm{g} / \mathrm{m}^{3}\right.$ predito e $26,7 \mu \mathrm{g} /$ $\mathrm{m}^{3}$ observado), $23 / 08$ a $27 / 08\left(26,9 \mu \mathrm{g} / \mathrm{m}^{3}\right.$ predito e $21,5 \mu \mathrm{g} /$ $\mathrm{m}^{3}$ observado), $28 / 08$ a $31 / 08\left(20,7 \mu \mathrm{g} / \mathrm{m}^{3}\right.$ predito e $21,0 \mu \mathrm{g} /$ $\mathrm{m}^{3}$ observado), $01 / 09$ a 03/09 $\left(16,5 \mu \mathrm{g} / \mathrm{m}^{3}\right.$ predito e $26,1 \mu \mathrm{g} /$ $\mathrm{m}^{3}$ observado), 09/09 a 12/09 $\left(17,5 \mu \mathrm{g} / \mathrm{m}^{3}\right.$ predito e $14,5 \mu \mathrm{g} /$ $\mathrm{m}^{3}$ observado) e $26 / 09$ a $28 / 09\left(17,7 \mu \mathrm{g} / \mathrm{m}^{3}\right.$ predito e $7,7 \mu \mathrm{g} /$ $\mathrm{m}^{3}$ observado). Nota-se que os resultados das simulações representaram satisfatoriamente a tendência de queda nos níveis de concentração durante os períodos de passagem da frente fria. Esse comportamento fica evidente a partir do dia $15 / 09$, quando diversos sistemas frontais atingiram a região, conduzindo a uma diminuição significativa dos níveis de concentração observados. Nos resultados da modelagem, apesar de não se considerar os efeitos da deposição úmida, a influência dos sistemas frontais sobre o nível de concentração pode ser explicado a partir da modificação do padrão de vento na região obtido dos dados meteorológicos de superfície do 


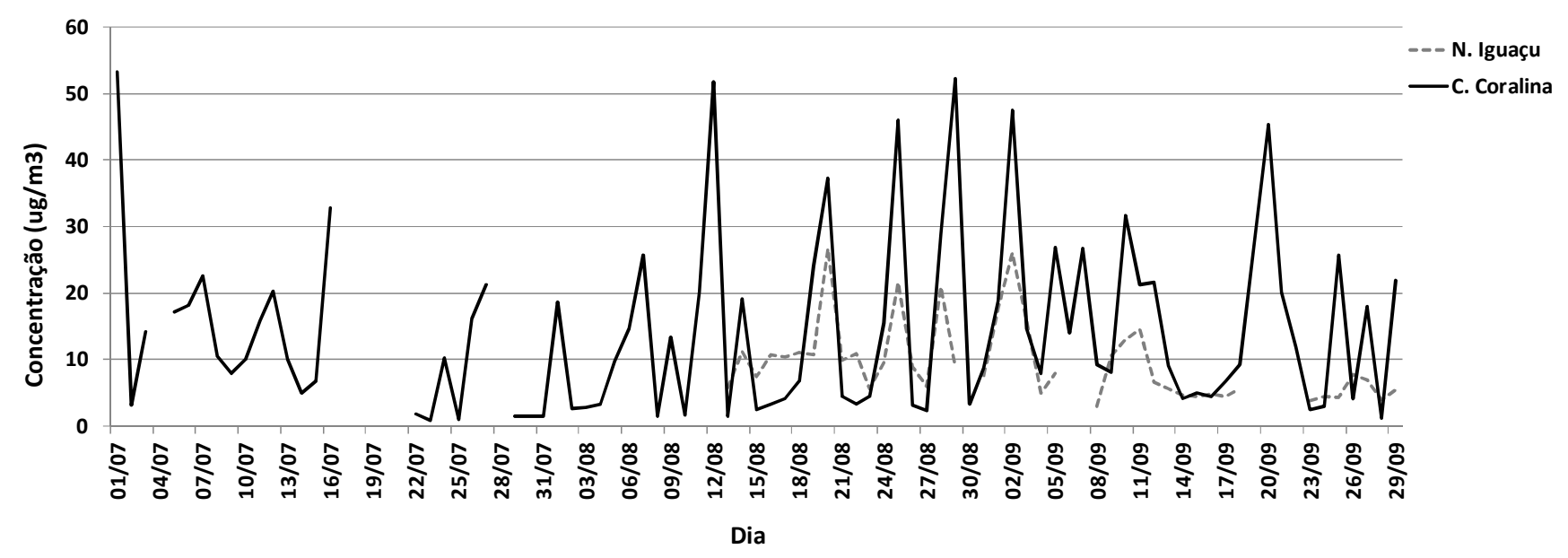

Figura 6 - Variabilidade temporal da concentração $(\mu \mathrm{g} / \mathrm{m} 3)$ médias de 24 horas observada durante o período de estudo para Nova Iguaçu e Cora Coralina.

código METAR. Sob a atuação desses sistemas de baixa pressão, o regime de vento na região indica ventos de sudoeste transportando o poluente para áreas distantes da região de Nova Iguaçu. Nota-se que principalmente os resultados do modelo transiente CALPUFF reproduziram corretamente essa condição. Para a estação de monitoramento Cora Coralina (Figura 8) nota-se que em alguns horários os resultados do AERMOD são inferiores aos do CALPUFF e em outros ocorre uma situação inversa. No entanto, deve-se destacar de uma forma geral que os resultados dos modelos apresentam valores superiores aos dados do monitoramento, evidenciando uma tendência conservadora para superestimar as concentrações nas proximidades das principais fontes de emissão (fontes fixas do pólo petroquímico de Duque de Caxias), sendo essa uma característica esperada em modelos usados para fins regulatórios. Destaca-se que os resultados do CALPUFF apresentaram sistematicamente valores similares aos obtidos na estação de monitoramento de Cora Coralina, inclusive para os picos de concentração, indicando uma melhor representação do mecanismo de dispersão de poluentes nas proximidades das fontes de emissão que o modelo AERMOD.

Os resultados Quantil-Quantil (Q-Q plot), apresentados na Figura 9, são utilizados como um critério de avaliação que demonstra a habilidade dos modelos em simular os picos de concentração sem levar em consideração o período de ocorrência, tornado-se indispensável em avaliações regulatórias. A análise dos resultados para as duas estações de monitoramento mostram que as simulações com o CALPUFF conduziram à maior concordância com os dados do monitoramento, e que os resultados do AERMOD sistematicamente apresentaram valores de pico abaixo dos obtidos com o CALPUFF. Deve-se destacar que os resultados simulados com o modelo lagrangeano apresentaram maior concordância com as concentrações de pico monitoradas para a estação Cora Coralina do que os obtidos para Nova Iguaçu. Para a estação de Nova Iguaçu as concentrações, simuladas com o AERMOD, tenderam a subestimar as concentrações observadas considerando toda a série de dados, enquanto as obtidas com CALPUFF tiveram

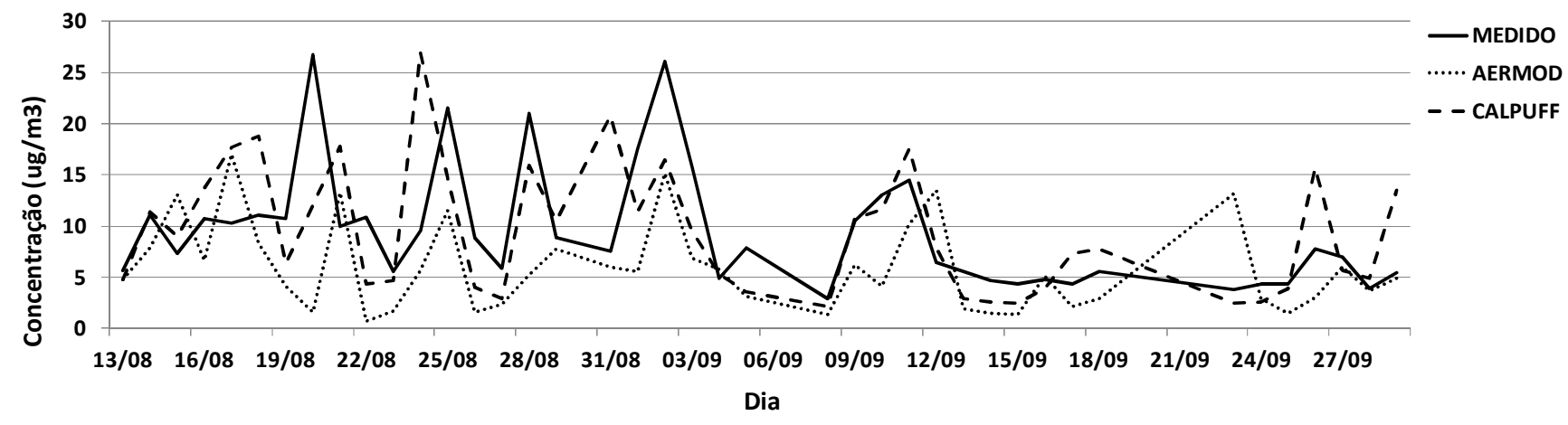

Figura 7 - Comparação temporal das concentrações $(\mu \mathrm{g} / \mathrm{m} 3)$ médias de 24 horas observadas e simuladas pelos modelos AERMOD e CALPUFF para o receptor Nova Iguaçu. 


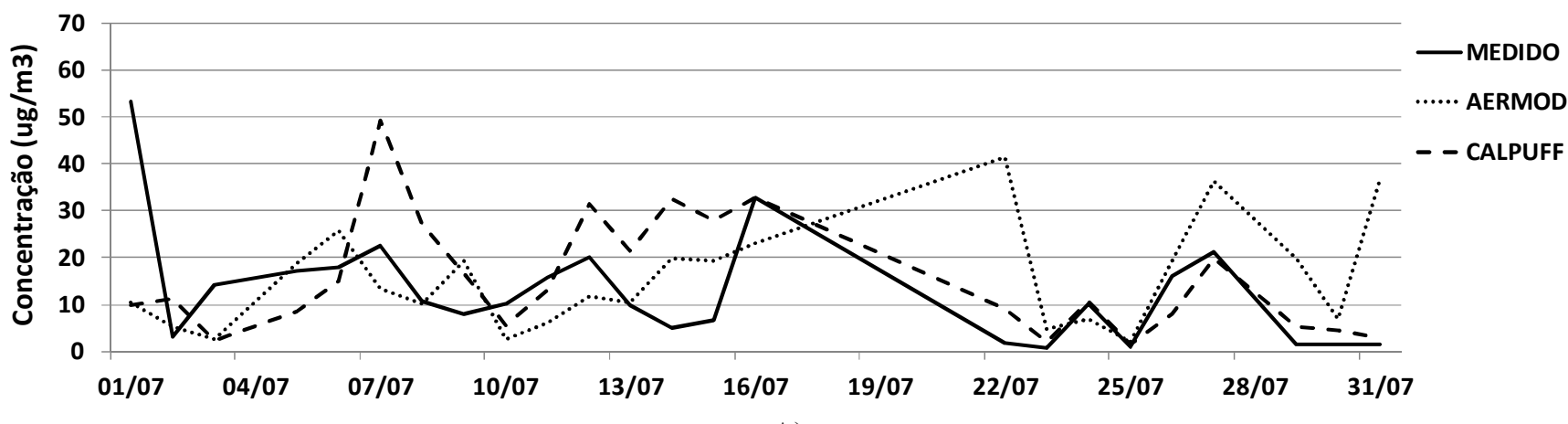

A)

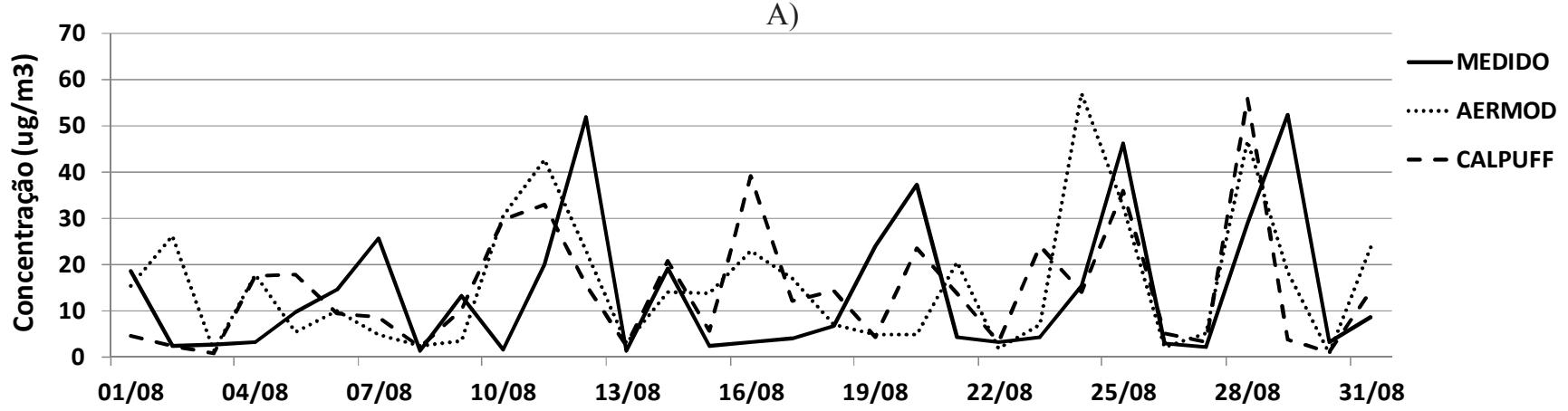

B)

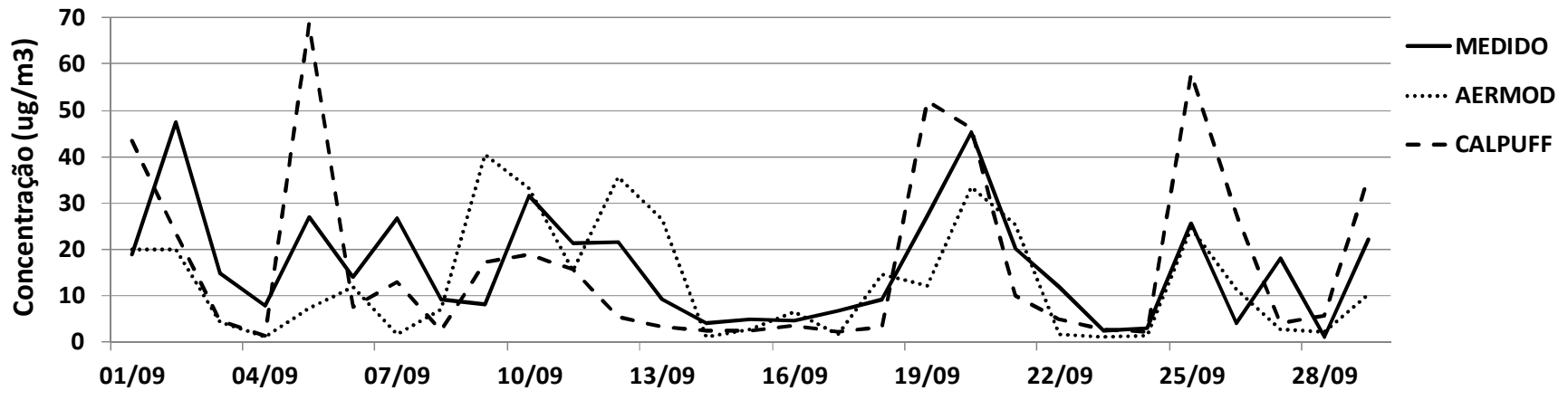

C)

Figura 8 - Comparação temporal das concentrações $(\mu \mathrm{g} / \mathrm{m} 3)$ médias de 24 horas observadas e simuladas pelos modelos AERMOD e CALPUFF para o receptor Cora Coralina. Mês de julho (a), mês de agosto (b) e mês de setembro (c).

uma alternância desse comportamento, porém sempre com uma melhor representação dos valores observados. Nota-se ainda para esta estação, que as menores concentrações simuladas com o AERMOD (abaixo de $5 \mu \mathrm{g} / \mathrm{m}^{3}$ ) subestimaram os menores valores observados com desvios acima de um fator de 2. Para a estação Cora Coralina os resultados de ambas as simulações apresentaram valores próximos dos observados e entre si, destacando-se que para todas as comparações os resultados dos modelos se mantiveram dentro de um fator de 2 .

A análise da Figura 10 permite avaliar o comportamento da distribuição espacial das máximas concentrações médias de 24 horas simuladas pelo CALPUFF e AERMOD respectivamente, considerando o domínio de estudo. As maiores concentrações simuladas por ambos os modelos ocorreram próximas as principais fontes emissoras de $\mathrm{SO}_{2}$ e não ultrapassaram o valor de $300 \mu \mathrm{g} / \mathrm{m}^{3}$, indicando para a região valores inferiores ao padrão primário de qualidade do ar $\left(365 \mu \mathrm{g} / \mathrm{m}^{3}\right)$. Observa-se na maior parte do domínio que as concentrações máximas simuladas com o AERMOD e CALPUFF se mantiveram abaixo de $50 \mu \mathrm{g} / \mathrm{m}^{3}$. Na comparação entre as simulações, destaca-se que os resultados do CALPUFF indicaram uma maior distribuição espacial das concentrações do que o obtido com o AERMOD, sendo uma tendência característica dos modelos transientes, devido a melhor representação da variabilidade espacial e temporal associadas aos sistemas meteorológicos atuantes na região. Vale ressaltar que na análise do mapa de dispersão de poluentes verifica-se uma maior influência da presença da topografia sobre os resultados do CALPUFF, onde 
(a) Nova Iguaçu

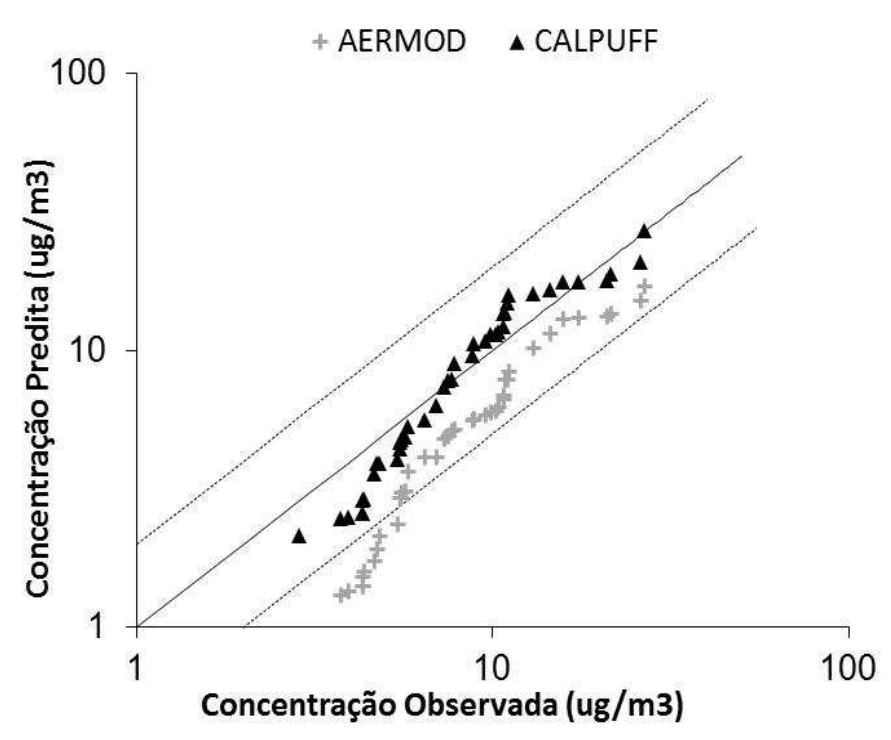

(b) Cora Coralina

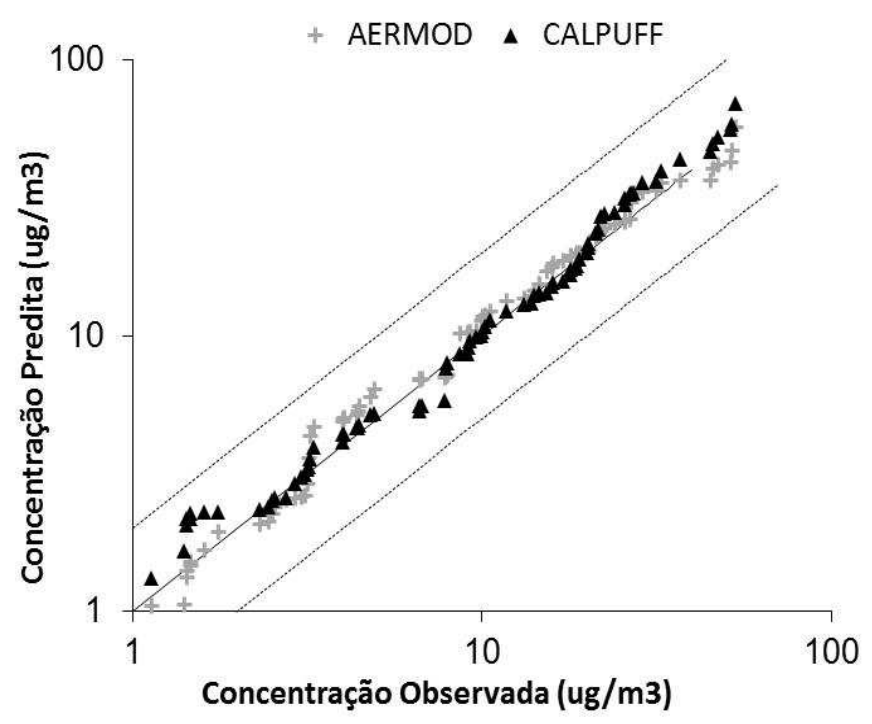

Figura 9 - Gráficos de dispersão para os resultados de Nova Iguaçu (a) e Cora Coralina (b).

destaca-se a ocorrência de picos de concentrações simulados nas proximidades das encostas dos principais maciços e a sotavento da área onde estão concentradas as principais fontes emissoras de dióxido de enxofre na Bacia Aérea III da RMRJ.

\subsection{Análises estatísticas das simulações}

Os resultados dos índices estatísticos, dispostos nas Tabelas 4 e 5, permitem uma avaliação quantitativa das discrepâncias entre as simulações e os dados monitorados.
Os coeficientes de correlação obtidos para a estação de Nova Iguaçu e Cora Coralina indicam que o CALPUFF, provavelmente devido a sua concepção transiente, representa o comportamento dos dados observados de forma mais realística que o AERMOD, principalmente para a estação de Nova Iguaçu.

Com o índice DFP avalia-se a variabilidade amostral entre os resultados preditos e observados, indicando uma análise comparativa entre a dispersão em torno da média obtida para os resultados simulados e os dados monitorados. Para a estação de Nova Iguaçu, o valor obtido com o CALPUFF foi significativamente superior ao índice referente ao AERMOD, sendo esse comportamento inverso para a estação de Cora Coralina. Vale destacar que nas duas localizações os índices estatísticos apresentaram valores satisfatórios, indicando que apesar da figura de dispersão mostrar grande variabilidade amostral para os resultados das simulações, principalmente para a estação de Cora Coralina, o comportamento médio da dispersão relativa às simulações é similar ao comportamento médio da dispersão dos dados observados.

Segundo a literatura científica (Arya, 1999; USEPA, 1992), a avaliação do índice DF é extremamente importante na análise de modelos regulatórios de qualidade do ar, revelando o comportamento médio do modelo para subestimar ou superestimar a concentração média observada. Segundo Arya (1999), os valores aceitáveis de DF para um modelo de qualidade do ar devem estar entre $-0,67$ a $+0,67$. A USEPA utiliza esse índice como uma primeira análise do desempenho dos modelos, descartando aqueles que apresentem valores de DF fora desses limites. Os resultados dos modelos mostraram-se satisfatórios para ambas as estações de monitoramento, sendo o valor obtido com o CALPUFF significativamente superior ao do AERMOD para o monitoramento em Nova Iguaçu, com o desempenho do modelo gaussiano indicando uma tendência a subestimar os dados monitorados, o que não é recomendável para modelos de qualidade do ar de uso regulatório.

O FA2 é proposto pela comunidade científica para estimar a porcentagem das concentrações simuladas que estão dentro de um erro de até $100 \%$ em relação às concentrações medidas. Segundo Arya (1999) um limiar variando de 0,4 a 0,5 deve ser utilizado para determinar se um modelo é propício para uso regulatório em uma região. $\mathrm{O}$ valor obtido com o CALPUFF para Nova Iguaçu foi significativamente superior ao do AERMOD e demonstra a potencialidade do modelo Lagrangeano para uso em situações near field, indicando que cerca de $78 \%$ dos resultados da simulação estão dentro dos limites aceitáveis para modelos regulatórios. O valor obtido com o modelo Gaussiano foi 51\%, valor próximo do limite de confiabilidade estabelecido. Para a estação de Cora Coralina os modelos apresentaram índices similares entre si com valores inferiores aos obtidos para Nova Iguaçu, mostrando novamente 


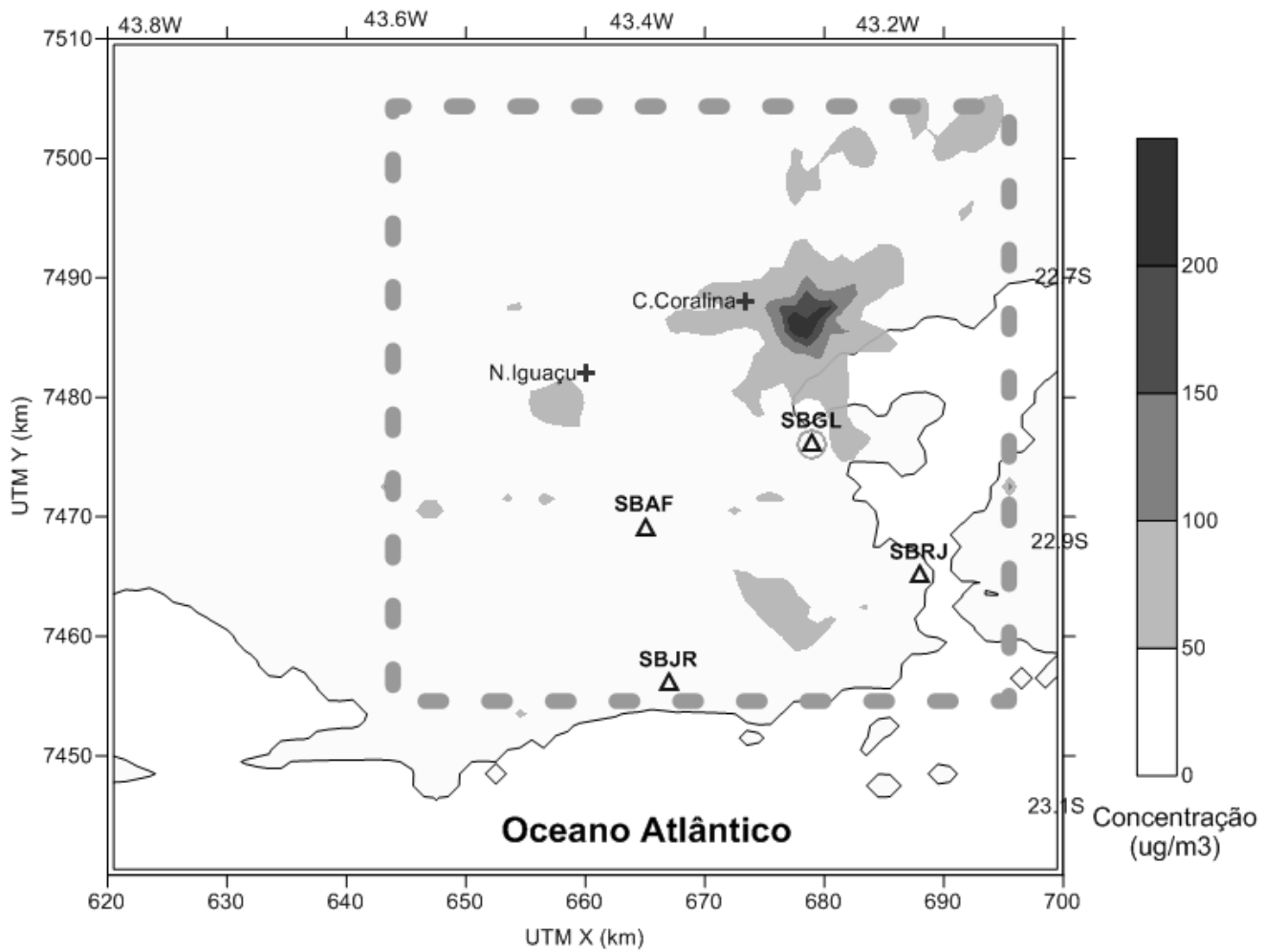

(a)

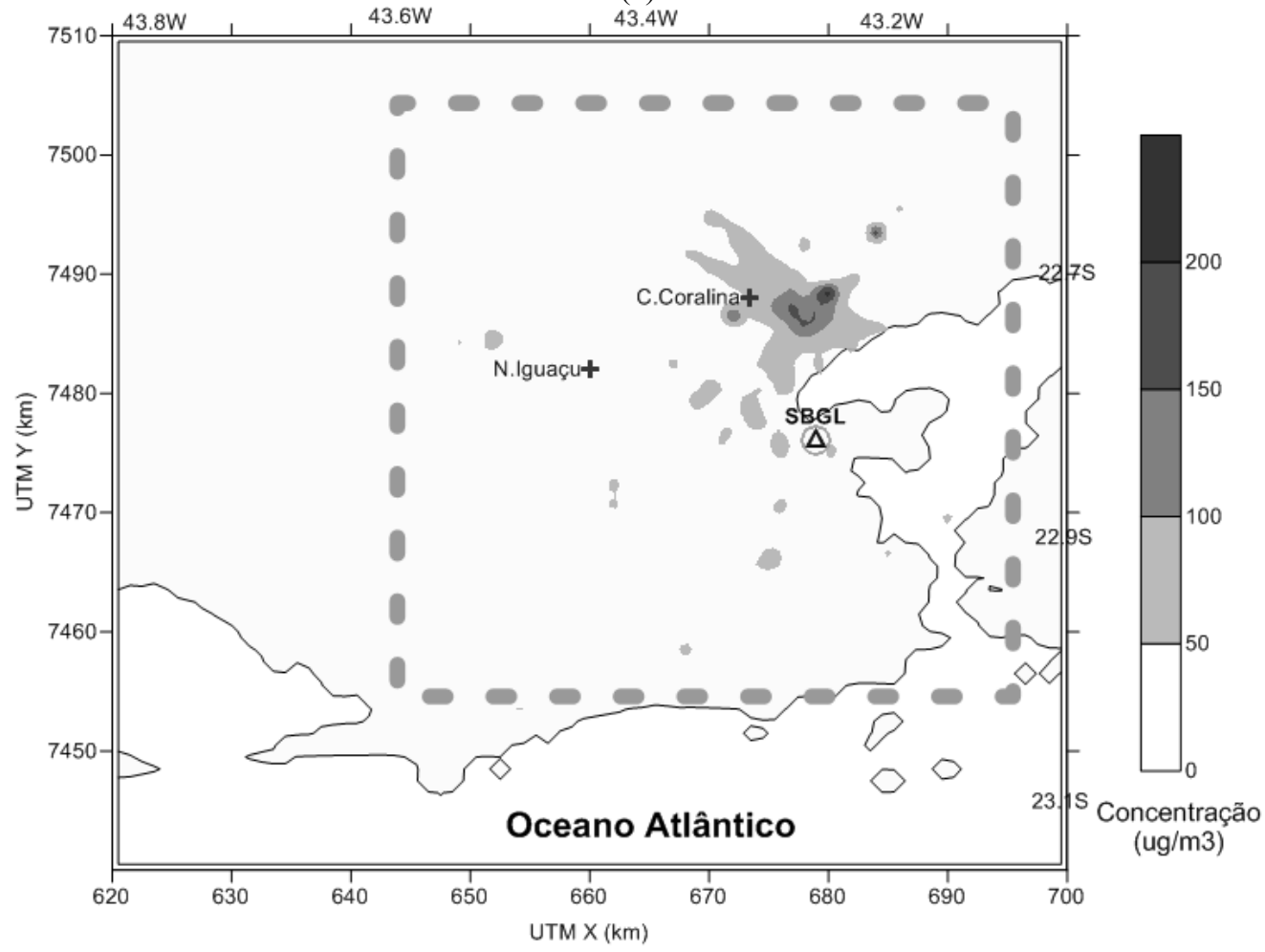

(b)

Figura 10 - Mapa com as máximas concentrações médias de 24 horas simuladas pelo CALPUFF (a) e pelo AERMOD (b). As cruzes representam as estações de monitoramento de qualidade do ar de Nova Iguaçu e Cora Coralina, os triângulos e círculos representam as estações meteorológicas de superfície e altitude respectivamente utilizadas no estudo. 
que na região circunvizinha as principais fontes de emissão, os modelos sistematicamente apresentam um desempenho inferior. Esse comportamento pode estar associado a não consideração da turbulência induzida pelas construções devido à proximidade do parque industrial da REDUC, afetando o processo de dispersão do poluente. Os dois modelos permitem incluir esse efeito na modelagem da qualidade do ar através do módulo disponível nos modelos intitulado Building Downwash. No entanto, para ativar o processamento do efeito da turbulência induzida nos modelos é necessário um arquivo contendo informações da estrutura física da planta industrial, que não está disponível.

Com relação ao EMQN, a simulação com o CALPUFF demonstra índices ligeiramente superiores ao obtido com o AERMOD para as duas estações de monitoramento, indicando valores satisfatórios para ambos os modelos.

As concentrações máximas e médias do período simuladas pelo CALPUFF apresentaram maior concordância com os dados observados para Nova Iguaçu do que os valores com o AERMOD, em que essas concentrações subestimaram os dados monitorados, com um percentual de $36 \%$ de diferença em relação à concentração máxima observada e 38\% para a concentração média. Para a estação de Cora Coralina as concentrações máximas e médias do período, obtidas com o CALPUFF, superestimaram os valores medidos e apresentaram discrepâncias maiores com estes do que o obtido com o AERMOD.

\section{CONCLUSÕES}

A avaliação das concentrações de $\mathrm{SO}_{2}$ simuladas pelos modelos regulatórios AERMOD e CALPUFF, em comparação com os dados de concentração observados, foi realizada através de índices estatísticos, gráficos Q-Q plot e mapas de concentração. De forma geral, os resultados da avaliação do desempenho dos modelos, a partir dos índices estatísticos, indicaram os melhores resultados para o receptor localizado em Nova Iguaçu, onde a distância em relação a principal fonte emissora (REDUC) dista cerca de $18 \mathrm{Km}$. Para a avaliação com relação aos picos de concentração com os resultados QuantilQuantil (Q-Q plot), a comparação entre as simulações e os dados de monitoramento indicaram maior concordância para o receptor Cora Coralina localizado dentro de um raio de $5 \mathrm{Km}$ a partir da principal fonte emissora (REDUC).

Observou-se que o desempenho do CALPUFF sistematicamente superou o AERMOD para as análises desenvolvidas para as situações near field na Bacia Aérea III da RMRJ. Os modelos apresentaram tendências opostas, onde o comportamento das simulações com o CALPUFF indicaram a superestimativa dos dados monitorados, enquanto as estimativas com o AERMOD conduziram a valores inferiores aos dados medidos. Essa tendência do AERMOD pode estar associada a desconsideração dos períodos de calmaria na modelagem da dispersão de poluentes, devido as considerações na concepção gaussiana do modelo, conduzindo a menores valores de concentrações. Essa característica da abordagem gaussiana evidencia limitações para uso em regiões com altos índices de calmaria como a Bacia Aérea III da RMRJ, sendo uma importante averiguação para estudos futuros considerando séries temporais para períodos mais longos. O modelo CALPUFF apresentou um padrão mais conservativo, uma característica recomendada para modelos regulatórios. A habilidade do sistema CALPUFF para assimilar dados meteorológicos de diferentes estações de monitoramento, representando a variabilidade

Tabela 4 - Resultados estatísticos do AERMOD e CALPUFF em relação aos observados em Cora Coralina, concentrações máximas e médias para o período $(\mu \mathrm{g} / \mathrm{m} 3)$.

\begin{tabular}{l|c|c|c}
\hline \multirow{2}{*}{\multicolumn{1}{c|}{ Índices }} & \multicolumn{2}{|c|}{ Predito } & \multirow{2}{*}{ Observado } \\
\cline { 2 - 3 } & CALPUFF & AERMOD & \\
\hline COR & 0.41 & 0.27 & - \\
\hline DFP & 0.28 & -0.09 & - \\
\hline DF & -0.08 & -0.03 & - \\
\hline FA2 & 0.42 & 0.42 & - \\
\hline EMQN & 1.09 & 1.16 & - \\
\hline Conc. Máxima & 68.82 & 57.05 & 53.27 \\
\hline Conc. Média & 15.54 & 14.72 & 14.35 \\
\hline
\end{tabular}


Tabela 5 - Resultados estatísticos do AERMOD e CALPUFF em relação aos observados em Nova Iguaçu, concentrações máximas e médias para o período $(\mu \mathrm{g} / \mathrm{m} 3)$.

\begin{tabular}{l|c|c|c}
\hline \multirow{2}{*}{ Índices } & \multicolumn{2}{|c|}{ Predito } & \multirow{2}{*}{ Observado } \\
\cline { 2 - 4 } & CALPUFF & AERMOD & \\
\hline COR & 0.52 & 0.31 & - \\
\hline DFP & 0.09 & -0.61 & - \\
\hline DF & 0.00 & 0.47 & - \\
\hline FA2 & 0.78 & 0.51 & - \\
\hline EMQN & 0.39 & 0.90 & - \\
\hline Conc. Máxima & 26.84 & 17.03 & 26.75 \\
\hline Conc. Média & 9.46 & 5.87 & 9.47 \\
\hline
\end{tabular}

espacial e temporal das condições meteorológicas, juntamente com a concepção física do modelo lagrangeano, que apresenta uma formulação transiente, possibilita uma modelagem mais realística dos sistemas meteorológicos atuantes na região. Essa característica é evidenciada nos mapas de concentração de poluentes.

É importante enfatizar que a instalação de estações meteorológicas próximas das grandes áreas poluidoras e a aplicação destes dados em estudos extensivos, associado a um maior aprofundamento do uso do fator peso destes dados, são requisitos necessários para se obter simulações da dispersão de poluentes mais realísticas na RMRJ, principalmente para estudos considerando modelos com características similares ao CALPUFF, onde permite-se a assimilação de informações de diversas bases de dados meteorológicos de superfície e altitude. Nota-se que, se por um lado os resultados apresentados não permitem uma consolidação da análise, devido a limitação associada ao período de apenas três meses para a avaliação estatística dos resultados, envolvendo apenas uma estação do ano e não possibilitando considerar a influência sazonal, por outro, evidencia-se que a recomendação de uso de modelos de qualidade do ar com finalidade regulatória, aplicados a RMRJ, deve ser repensada com o intuito de contribuir para o aprimoramento da gestão ambiental na região.

\section{AGRADECIMENTOS}

Ao Instituto Estadual do Ambiente (INEA), por ceder os dados medidos de concentração. À Aeronáutica, por disponibilizar os dados meteorológicos no site www.redemet. aer.mil.br. Ao CNPq e FAPERJ, por financiar e subsidiar todo o estudo.

\section{REFERÊNCIAS BIBLIOGRÁFICAS}

ARYA, S.P. Air Pollution Meteorology and Dispersion. New York, Oxford University Press, 310 p. 1999.

BALANESCU, M.; HRITAC, M.; MELINTE, I.; NICOLAE, A. Environmental impact assessment of an industrial accident using ISC - AERMOD VIEW. A CASE STUDY. In: Harmonisation within Atmospheric Dispersion Modelling for Regulatory Purposes, 9, 2004, Garmisch-Partenkirchen, Alemanha. Proceedings 9th conference on Harmonisation within Atmospheric Dispersion Modelling for Regulatory Purposes, Garmisch-Partenkirchen, Alemanha, 2004. p. 346-350.

BRODE, R. W. CALPUFF Near Field Validation. In: 10 $^{\text {th }}$ Conference on Air Quality Modeling, 3, 2012, Research Triangle Park, North Carolina, U.S. Environmental Protection Agency. 2012.

DONALDSON, I.; HARRISON, D.; HILL, J. Performance of AERMOD vs. CALPUFF Fugitive Emission Sources in the Near field. In: A\&WMA Annual Conference, 101., 2008. 101st Annual Conference \& Exhibition. pp. 26. 2008

ELBIR, T. Comparison of Model Predictions With The Data of An Urban Air Quality Monitoring Network in Izmir, Turkey. Atmospheric Environment, v. 37, n. 15, p. 21492157, 2003.

FEEMA - Fundação Estadual de Engenharia do Meio Ambiente. Inventário de Fontes Emissoras de Poluentes Atmosféricos da Região Metropolitana do Rio de Janeiro. Rio de Janeiro - RJ, Brasil, 2004.

INEA - INSTITUTO ESTADUAL DO AMBIENTE. Relatório Anual da Qualidade do Ar do Estado do Rio de Janeiro. Rio de Janeiro - RJ, Brasil, 2009. 
HANNA, S.R. Air Quality Model Evaluation and Uncertainty. Journal of the Air Pollution Control Association, v. 38, n.4, p.406-412, 1988.

HANNA, S. R. and J. S. Chang. Hybrid Plume Dispersion Model (HPDM), improvements and testing at three field sites. Atmospheric Environment, 27A, 1491-1508, 1993.

MME - Ministério de Minas e Energia. Novo Marco Regulatório: Pré-sal e áreas estratégicas. Brasil, 2009.

MORAES, M. R. Ferramenta para a Previsão de Vento e Dispersão de Poluentes na Microescala Atmosférica. 2004. 143 p. Tese (Doutorado em Engenharia Mecânica) Departamento de Engenharia Mecânica/UFSC, Florianópolis - SC, Brasil, 2004.

MOREIRA, D.; TIRABASSI, T. Modelo Matemático de Dispersão de Poluentes na Atmosfera: Um Instrumento Técnico para a Gestão Ambiental. Ambiente \& Sociedade, v. 7, n. 2, 2004.

OSHAN, R.; KUMAR, A. MASURAHA, A. Application of the USEPA's CALPUFF Model to an Urban Area. Environmental Progress, v. 25, n. 1, p. 12-17, 2006.

PERRY, S.G.; CIMORELLI, A.J.; PAINE, R.J.; BRODE, R.W.; WEIL, J.C.; VENKATRAM, A.; WILSON, R.B.; LEE, R.F.; PETERS, W.D.; AERMOD: A Dispersion Model for Industrial Source Applications. Part II: Model Performance Against 17 Field Study Databases. Journal of Applied Meteorology, v.44, pp. 694-708, 2005.

PIMENTEL, L. C. G.; SOARES da SILVA, M. S.; LANDAU, L.; PEREZ GUERRERO, J. S. Performance assessment of regulatory air quality models AERMOD and CALPUFF - a near field case study in metropolitan region of Rio de Janeiro, Brazil. In: International Conference on Harmonisation within Atmospheric Dispersion Modeling for Regulatory Purposes, 13., 2010, Paris, França. Proceedings of the 13th International International Conference on Harmonisation within Atmospheric Dispersion Modeling for Regulatory Purposes. Paris, França, 2010.

PIMENTEL, L.C.G.; MARTON, E.; SOARES da SILVA, M.; JOURDAN, P. Caracterização do regime de vento em superfície na Região Metropolitana do Rio de Janeiro. Eng. Sanit. Ambient., v.19, n.2, pp. 121-132. 2014

SCIRE, J.S. et al. A User's Guide for the CALMET Meteorological Model (Version 5). Concord, MA: Earth Tech Inc. 2000a. 316 p.

SCIRE, J.S.; STRIMAITIS, D.G.; YAMARTINO, R.J. A User's Guide for the CALPUFF Dispersion Model (Version 5.0). Massachusetts, U.S. Earth Tech, Inc. 2000b. 468 p.

SEANGKIATIYUTH, K. et al. Application of the AERMOD modeling system for environmental impact assessment of $\mathrm{NO}_{2}$ emissions from a cement complex. Journal of Environmental Sciences, v. 23(6), p. 931-940. 2011.
SIDLE, C.; TUCKETT-JONES, B.; NG, B.; SHI, P. Model intercomparison between ADMS 3.1, AERMOD and AERMOD PRIME. In: Harmonisation within Atmospheric Dispersion Modelling for Regulatory Purposes, 9, 2004, Garmisch-Partenkirchen, Alemanha. Proceedings 9th conference on Harmonisation within Atmospheric Dispersion Modelling for Regulatory Purposes, Garmisch-Partenkirchen, Alemanha, 2004. p. 156-160.

SOARES, M.S. Avaliação do Sistema De Modelagem CALPUFF aplicado ao dióxido de enxofre para as Bacias Aéreas I, II e III da Região Metropolitana do Rio de Janeiro. Monografia (Bacharelado em Meteorologia) - Departamento de Meteorologia/IGEO - UFRJ, Rio de Janeiro, RJ, Brasil. 2010.

USEPA- United States Environmental Protection Agency. Protocol for Determining the Best Performing Model. EPA-454/R-92-025. Research Triangle Park - NC. 1992.

USEPA- United States Environmental Protection Agency. User's Guide for the Industrial Source Complex (ISC3) Dispersion Models (revised) Volume II - Description of Model Algorithms, In: EPA-454/b-95-003b, North Carolina, U.S.A., 1995

USEPA - United States Environmental Protection Agency. Comparison of regulatory Design Concentrations AERMOD vs ISCST3, CTDMPLUS, ISC-PRIME. U.S. ENVIRONMENTAL PROTECTION AGENCY, In: EPA454/R-03-002, June, 2003.

USEPA - United States Environmental Protection Agency. AERMOD: Description of Model Formulation. EPA454/R-03-004. North Carolina, U.S. Environmetal Protection Agency, 2004.

USEPA - United States Environmental Protection Agency. Revision to the Guideline on Air Quality Models: Adoption of a Preferred General Purpose (Flat and Complex Terrain) Dispersion Model and Other Revisions, 40 CFR Part 51, Appendix W. Research Triangle Park, NC: U.S. Environmental Protection Agency, Published in the Federal Register, v. 70, n. 216, November 9, 2005.

USEPA - United States Environmental Protection Agency. Clarification of Regulatory Status of CALPUFF for Nearfield Applications. Staff Memorandum, Research Triangle Park, NC: U.S. Environmental Protection Agency, 2008.

USEPA - United States Environmental Protection Agency. Documentation of the Evaluation of CALPUFF and Other Long Range Transport Models Using Tracer Field Experiment Data. EPA-454/R-12-003. Research Triangle Park - NC. 2012.

VELLOSO, M.F.A. Avaliação de modelos gaussianos para fins regulatórios - um estudo para a Bacia Aérea III da Região Metropolitana do Rio de Janeiro. Dissertação 
(Mestrado em Engenharia Mecânica) - Departamento de Engenharia Mecânica/UFRJ, Rio de Janeiro, RJ, Brasil. 2007.

VENKATRAM, A.; WYNGAARD, J. C. Lectures on Air Pollution Modeling. American Meteorological Society, Boston, 390pp. 1988.

VENKATRAM, A.; ISAKOV, V.; PANKRATZ, D.; YUAN, J. Modeling Dispersion at Distances of Meters from Urban Sources, Atmospheric Environment, v.38, pp. 4633-4641, 2004.

VICENTINI, P. C. Uso de Modelos de Qualidade do Ar para a Avaliação do Efeito do PROCONVE entre 2008 e 2020 na Região Metropolitana do Rio de Janeiro. 2011. 224 p. Tese (Doutorado em Engenharia Mecânica) - Departamento de Engenharia Mecânica - COPPE - Universidade Federal do Rio de Janeiro, Rio de Janeiro, RJ, Brasil. 2011.

VICENTINI, P.C.; PIMENTEL, L.C.G; SOARES, M.S.; PONTES, A.S. Efeitos do PROCONVE na região metropolitana do Rio de Janeiro entre 2008 e 2020 avaliação como uso de inventário de emissões e de modelo de qualidade do ar. In: Simpósio Internacional de Engenharia Automotiva , 19., 2011, São Paulo. Anais do XIX Simpósio Internacional de Engenharia Automotiva - SIMEA. São Paulo, 2011.
YAU, K.; MACDONALD, R.W.; THÉ J.L. Inter-comparison of the AUSTAL2000 and CALPUFF dispersion models against the KINCAID data set. In: International Conference on Harmonisation within Atmospheric Dispersion Modelling for Regulatory Purposes, 9., 2004, Garmisch-Partenkirchen, Germany. Proceedings of the 9th International Conference on Harmonisation within Atmospheric Dispersion Modelling for Regulatory Purposes, Garmisch-Partenkirchen, Germany, 2004.

Zannetti, P. Air Pollution Modeling Teories, Computational Methods and Available Software, New York: Kluwer Academic Publisher, 1990. 444p. 